\title{
The Function of MicroRNAs in B-Cell Development, Lymphoma, and Their Potential in Clinical Practice
}

\author{
Bing Zheng ${ }^{1,2}$, Zhijiang Xi ${ }^{1,2}$, Rong Liu ${ }^{1,2}$, Wei Yin ${ }^{3}$, Zhiwei Sui ${ }^{4}$, Boxu Ren ${ }^{1,2}$, \\ Heather Miller ${ }^{5}$, Quan Gong ${ }^{1,2 *}$ and Chaohong Liu ${ }^{6 *}$
}

'Department of Immunology, School of Medicine, Yangtze University, Jingzhou, China, ${ }^{2}$ Clinical Molecular Immunology Center, School of Medicine, Yangtze University, Jingzhou, China, ${ }^{3}$ Wuhan Children's Hospital, Tongji Medical College, Huazhong University of Science and Technology, Wuhan, China, ${ }^{4}$ Division of Medical and Biological Measurement, National Institute of Metrology, Beijing, China, ${ }^{5}$ Department of Intracellular Pathogens, National Institute of Allergy and Infectious Diseases, Bethesda, MD, United States, ${ }^{6}$ Department of Microbiology, School of Basic Medicine, Tongji Medical College, Huazhong University of Science and Technology, Wuhan, China

\section{OPEN ACCESS}

Edited by: Michael R. Gold, University of British Columbia, Canada

Reviewed by: Rodney P. DeKoter, University of Western

Ontario, Canada

Li-Fan Lu,

University of California, San Diego, United States

${ }^{*}$ Correspondence: Quan Gong gongquan1998@163.com Chaohong Liu chaohongliu80@126.com

Specialty section: This article was submitted to B Cell Biology, a section of the journal

Frontiers in Immunology

Received: 17 January 2018 Accepted: 16 April 2018 Published: 30 April 2018

Citation:

Zheng B, Xi Z, Liu R, Yin W, Sui Z, Ren B, Miller H, Gong $Q$ and Liu C (2018) The Function of MicroRNAs in $B$-Cell Development, Lymphoma, and

Their Potential in Clinical Practice.

Front. Immunol. 9:936. doi: 10.3389/fimmu.2018.00936
B-cell formation, development, and differentiation are complex processes regulated by several mechanisms. Recently, there has been growing evidence indicating that microRNAs (miRNAs) are important for normal B-cell lineage development. miRNAs are small non-coding RNA molecules, about 20-22 nucleotide in length, that play an important role in regulating gene expression. They pair with specific messenger RNAs (mRNAs), resulting in mRNAs translational repression or degradation. Here, we review current research about the function of miRNAs in the aspects of B-cell physiology and pathology. We start by introducing the process of miRNA biogenesis. We will then focus on the role of miRNAs during B-cell lineage commitment and development in the bone marrow, followed by a discussion of miRNAs' role in subsequent peripheral B-cell activation, proliferation, and final differentiation (including B-cell central tolerance and autoimmunity). We list and describe several examples to illustrate miRNAs' role in the development of B-cell lymphoma, both as oncogenes and tumor suppressor genes. Finally, we delineate the potential value of miRNAs in diagnosing B-cell lymphoma, predicting clinical outcomes, and modulating the efficiency of anticancer treatments. Despite the vast amount of research conducted on miRNAs in recent years, it is still necessary to increase and further strengthen studies on miRNAs and their targets to promote a better understanding on B-cell development and as a result, construct more effective treatments against B-cell disease.

Keywords: B cell, microRNA, bone marrow, peripheral, germinal center, lymphoma, diffuse large B-cell lymphoma

\section{INTRODUCTION}

MicroRNAs (miRNAs) are small non-coding RNA molecules, generally 20-22 nucleotides long, that post-transcriptionally regulate gene expression in plants and metazoans $(1,2)$. miRNAs were first discovered in Caenorhabditis elegans. To date, about 2,500 human and 1,900 mouse miRNAs have been identified. Functional studies of miRNAs show that miRNAs regulate approximately $50 \%$ of all protein-coding genes. They are involved in most of the cellular physiological processes, including proliferation, development, and differentiation $(3,4)$. The changes of expression in miRNAs have been proven to be linked with many human pathologies.

Though miRNAs may be involved in several cellular physiological processes, do they regulate B-cell development? B-cell development includes several ordered steps, from the development of the 
$B$ cell and its early stages in the bone marrow in the absence of an antigen to later stages that occur after interaction with the antigen in the periphery with the final result of antibody synthesis. Many investigators have studied the expression and function of miRNAs during B cell development, and evidence suggests that the answer to the question just presented is "yes." Here, we provide a general overview of miRNAs' roles during B-cell development in the bone marrow and in the periphery. In addition, we explore the function of miRNA expression in B-cell malignancies (Table 1).

\section{miRNA BIOGENESIS}

MicroRNAs are processed from long hairpin-containing primiRNA transcripts. Pri-miRNAs are transcribed by RNA polymerase II and act as substrates for RNase III enzymes Drosha.
In the nucleus, pri-miRNAs are cleaved by Drosha to generate pre-miRNAs with 70 nucleotides in length, and then premiRNAs are exported to the cytoplasm, in which, it is further processed into miRNA duplexes of $\sim 22$ bp long by Dicer. One strand of the duplex is the mature miRNA; this mature strand is usually incorporated into the RNA-induced silencing complex (miRISC). Argonaute (AGO) proteins, the main components of the miRISC, then directly bind with mature miRNA strands to cause subsequent gene silencing. GW182 proteins interact with the AGO protein to mediate this gene silencing. Finally, miRISC binds to its target messenger RNAs (mRNAs) and this result in their translation inhibition or degradation of the mRNA (5). A single miRNA can simultaneously mediate large numbers of different target genes. Likewise, a single mRNA can be regulated by multiple miRNAs $(2,4)$.

TABLE 1 | MicroRNAs' (miRNAs') role in B-cell development, central tolerance, autoimmunity, and lymphoma.

\begin{tabular}{|c|c|c|c|}
\hline miRNA & Putative targets & Function & Reference \\
\hline miR-17-92 cluster & Bim & $\begin{array}{l}\text { Essential for fetal and adult B-cell development; promote the survival of early B-cell } \\
\text { progenitors (pro-B } \rightarrow \text { pre-B) }\end{array}$ & $(14,15)$ \\
\hline miR-34a & Foxp1 & Inhibit B cell development at the pro-B to pre-B cell stage & (16) \\
\hline miR-150 & c-Myb, Foxp1 & $\begin{array}{l}\text { High levels in the lymph nodes, spleen, and thymus, premature expression block } \\
\text { the transition from the pro-B to the pre-B stage }\end{array}$ & $(17,18)$ \\
\hline $\mathrm{miR}-212 / 132$ & Sox4 & Regulate the differentiation of prepro-B cells to pro-B cells and regulate B-cell survival & (22) \\
\hline \multicolumn{4}{|c|}{ Peripheral B-cell development } \\
\hline $\mathrm{miR}-146 \mathrm{a}$ & Numb & Regulate marginal zone B-cell differentiation & (30) \\
\hline \multirow[t]{2}{*}{ miR-155 } & $\begin{array}{l}\text { Activation-induced cytidine } \\
\text { deaminase }\end{array}$ & Regulate lg isotype switching and somatic hypermutation & $(31,32)$ \\
\hline & PU.1 & Essential for germinal center response and high-affinity lgG1 production & $(33,34)$ \\
\hline
\end{tabular}

B-cell central tolerance and autoimmunity

miR-17-92 cluster PTEN Control B cell central tolerance at the immature B cell stage;

Mice overexpressing the miR-17-92 cluster develop autoimmunity

$\operatorname{miR}-148 a$

Gadd45a, Bcl2111, and Pten

Regulate B cell central tolerance and autoimmunity, Increased miR-148a expression lead to lethal autoimmune disease in lupus mice

miR-210 Unknown

Mice deficient in miR-210 lead to production of autoantibodies; mice overexpressing miR-210 result in abnormalities in B cell subsets and function

\section{B-cell lymphoma}

miR-17-92 cluster miR-155

miR-21

miR-217

miR-181a

miR-34a

miR-146a

Cluster 15a/16-1

miRNAs

miR-28

\section{Unknown}

TGFBR2, NIAM, histone deacetylase 4, SHIP1, and PIK3R1 (p85 $\alpha)$

Unknown

Unknown

CARD11, NFKBIA, NFKB1, RELA/P65, and REL

FoxP1, AXL

Early growth response-1 gene BCL2

MAD2L1, BAG1
Accelerate tumor development in a mouse B-cell lymphoma model

Essential for cell proliferation, cell cycle, and apoptosis of diffuse large B-cell lymphoma

(DLBCL) cell lines; acts as an oncogenic miR in B-cell lymphoproliferative disorders

Act as oncomiR to initiate tumor formation and maintenance

Promote the GC reaction; its overexpression promotes mature B cell lymphomagenesis

Decrease cell proliferation and slower tumor growth rate by inhibiting NF-kB signaling activity

Inhibit the proliferation of various DLBCL cell lines; involve in the pathogenesis of DLBCL

Inhibit B-cell oncogenesis

Tumor suppressor in B-CLL and mantle cell lymphoma

$(69,70)$

Acts as a tumor suppressor in Burkitt lymphoma 


\section{B-CELL DEVELOPMENT}

B cells can be divided into B1 and B2 cell subclasses. B1 cells are components of the innate immunity and are characterized by a limited diversity of antigen receptors (6). B2 cells are conventional $\mathrm{B}$ cells and are involved in the adaptive humoral immune response. Going forward, B cells mentioned in this paper specifically refer to B2 cells. B-cell development initiates in the bone marrow with the asymmetric division of hematopoietic stem cells (HSCs). These HSCs then undergo successive differentiation to form common lymphoid progenitors that can further develop into either B cells or $\mathrm{T}$ cells. The majority of progenitors that remain in the bone marrow grow into B cells. Development of B cells continues in the bone marrow and peripheral lymph organs of an adult throughout his or her lifetime $(7,8)$.

Studies have shown that miRNAs play a crucial role in regulating the normal development of B cells. However, despite intensive study on miRNAs and B cells, the molecular pathways to regulate B-cell development is still not clear. Abnormal expression of miRNAs is considered to be closely associated with the pathogenic mechanism of B-cell malignant tumors, including mature and progenitor B-cell malignant tumors, such as non-Hodgkin lymphoma and B-lymphoblastic leukemia.

\section{miRNAs IN BONE MARROW B-CELL DEVELOPMENT}

A defining feature in B-cell development is the rearrangement of genes in the immunoglobulin (Ig) loci, which results in the acquisition of a specific BCR on the B-cell surface (9). These rearrangements lead to the formation of immunoglobulin heavy ( $\mathrm{IgH})$ chains during the pro-B cell stage and immunoglobulin light (IgL) chains during the pre- $\mathrm{B}$ stage. The process of genetic random recombination of variable $(\mathrm{V})$, joining $(\mathrm{J})$, and diverse $(\mathrm{D})$ gene segments, called $\mathrm{V}(\mathrm{D}) \mathrm{J}$ recombination, is mediated by RAG1 and 2 recombinases. At the end of this process, the immature B cell will acquire unique antigen specificity by expressing single $\operatorname{IgH}$ and IgL chains. Because the gene rearrangement is random, some pre-B cells will develop into immature autoreactive B cells. To remove or regulate autoreactive $B$ cells, newly developed $B$ cells will undergo the initial screening process through central tolerance mechanisms. If the $B$ cell receptor can specifically recognize its self-antigen, it will undergo further $\mathrm{V}(\mathrm{D}) \mathrm{J}$ recombination at the IgL chain or the autoreactive B cell will die by apoptosis. Otherwise, non-autoreactive $B$ cells will differentiate into mature B cells. Some B cells with self-reactivity can actually be further modulated through receptor editing in the periphery $(10,11)$.

To date, several miRNAs have been reported to act as antigenindependent modalities that are responsible for $\mathrm{B}$ cell development in the bone marrow. miR-181a was the first reported miRNA to affect $B$ cell differentiation in the bone marrow (12). Researchers found that miR-181a was upregulated in the bone marrow, thymus, and spleen. Furthermore, overexpression of miR-181a by retroviral transduction in HSCs substantially increased B cell lineage in both tissue-culture differentiation assays and in mice (12).

The miR-17-92 cluster is composed of six single mature miRNAs (including miR-17, 18a, 19a, 20a, 19b-1, and 92a-1) and two paralogs: miR-106a 363 and miR-106b 25 (13). The miR-17-92 cluster is important for fetal and adult B-cell development. Ventura et al. used miR-17-92-deficient mice and found that B-cell development is inhibited at the pro-B to pre-B stage differentiation through modulating proapoptotic protein, Bim. Mice deficient in the cluster die shortly after birth from ventricular septal defects and lung hypoplasia (14). In another study, Lai et al. (15) were able to rescue the pro- to pre-B transition defect in miR-17-92 knockout cells using a lentiviral vector to express the miR-17 subfamily of the cluster. These studies show the miR-17 subfamily is important for early B-cell development (15), but discrepancy exists between these two reports $(14,15)$. The study performed by Lai et al. (15) found the expression of Bim in pro-B cell is only slightly increased in Mb1tKO mice (B cell-specific deletion of the miR-17-92 family miRNAs) compared with WT mice, so the finding excluded the role of Bim in mediating early B-cell development at the pro- $B$ to pre- $B$ transition, suggesting that some distinct molecular pathways and target genes should be involved in regulating miR-17-92 family miRNA control of B cell development. The pro- $\mathrm{B}$ to pre- $\mathrm{B}$ transition seems to be also mediated by another miRNA, miR-34a (16), transduction of the mouse bone marrow cell with a retroviral vector expressing both miR-34a and GFP resulted in reduced mature B cells. Further studies indicate that $\mathrm{B}$-cell development is blocked at the pro-B to pre- $\mathrm{B}$ cell stage due to the involvement of miR-34a directly suppressing Foxp1, a B-cell oncogene (16).

miR-150 exhibits dynamic expression during B lymphopoiesis. Its expression is mainly in the spleen and lymph nodes; during $\mathrm{B}$ and $\mathrm{T}$ cell development, its levels greatly increase. Specifically, miR-150 expression increases strikingly at the immature B cell stage. When mouse bone marrow is transplanted with HSCs overexpressing miR-150 by a retroviral vector, the formation of mature B cells is extremely impaired. Additionally, the B-cell transition from the pro- $B$ to the pre- $B$ stage is blocked. Therefore, miR-150 might affect the pro- $B$ and pre- $B$ cell formation, a process regulated by targeting Myb and Foxp1, both of which are important for B-cell development $(17,18)$. miR-150 not only regulates the $\mathrm{B} 2$ cell development, but also affects the $\mathrm{B} 1$ cell formation in peripheral development and antibody response (17).

The miR-23a miRNA cluster includes three miRNAs: miR-23a, miR-24-2, and miR-27a. Its expression is regulated by the PU.1 transcription factor, which is indispensable for the immune cells differentiation from multipotential progenitors (19). Kurkewich et al. generated a miRNA-23a-,-24-2-, and -27a-deficient mouse model and observed that B lymphocytes in both the bone marrow and the spleen were significantly increased at the expense of myeloid cells (20). Increasing expression of miR-24-2 alone or the entire miR-23a miRNA cluster could simulate the function of PU.1 to facilitate hematopoietic stem cell differentiation into myeloid progenitors. This occurs at the expense of B cells both in vivo and in vitro (21). Therefore, miRNAs of the 23a cluster is also essential to regulate B cell lymphopoiesis.

The miR-212/132 cluster, identified in a recent study (22), has shown the ability to regulate B-cell development. In this research, B-cell development was inhibited when mice were transduced with a miR-132 overexpression vector. This inhibition occurred in the early B cell stage from prepro-B cell to pro-B cell. It was 
also found that the miR-212/132 cluster influences the survival of B cells. Another study proved that miR-132 regulates B-cell differentiation through inhibiting the transcription factor Sox 4 (22).

The above data suggested that bone marrow B-cell development is a complex differentiation program and the process can be regulated by some miRNAs through targeting transcription factors, such as c-Myb, Foxp1, and Sox4 (16-18, 22). Different miRNAs showed positive or negative roles in regulating B-cell development, such that miR-34a, miR-150, miR-23a miRNA cluster and miR-212/132 inhibit early B-cell progenitor survival, whereas miR181, miR-17-92 cluster promotes early B-cell differentiation from pro-B cells to pre-B cells. Undoubtedly, more miRNAs and their targets will be discovered to regulate the B-cell development in bone marrow, and miRNAs can mediate more complex gene expression.

\section{miRNAs IN PERIPHERAL B CELL DEVELOPMENT}

B-cell maturation occurs in the absence of antigen in the bone marrow and is then released into the periphery, where they recirculate among the lymphoid organs, lymph, and blood. The $B$ cells that have not been exposed to a specific antigen are called naïve $B$ cells. Once naïve B cells are exposed to an antigen, some of the activated $\mathrm{B}$ cells (ABCs) directly differentiate into short-lived antibody-producing cells that mainly secrete IgM. The other B cells enter the follicle to establish a germinal center (GC) and eventually differentiate into high-affinity IgG-producing plasma cells and memory cells. The process of B-cell differentiation into plasma cells is regulated by activating the transcription factors Blimpl an Xbp1 (23). GCs consist of three different regions that are termed dark zone, light zone, and mantle zone. The dark zone results from an intensive distribution of rapidly dividing B cells (centroblasts), whereas the light zone is made up of slower proliferating B cells (centrocytes) within the network of $\mathrm{T}$ follicular helper cells and follicular dendritic cells (DC). The non-ABCs are transferred to the border region of the follicle, forming the mantle zone. In the GC, B cells undergo Ig affinity maturation, where IgV genes are subjected to a series of somatic hypermutations, leading to differentiation into high-affinity antibody-producing plasma cells (24). Some autoreactive BCRs can be modified into non-autoimmune cells by a second V(D)J gene rearrangement. In addition, during the GC reaction, Ig genes undergo class switch recombination, and IgM constant regions are replaced by other Ig isotypes. This process results in generation of different effector functions of antibodies. Both somatic hypermutation and class switch recombination depend on the activity of activation-induced cytidine deaminase (AID) (25). Some centrocytes in the GC undergoing affinity maturation may eventually differentiate into long-lived memory B cells that can be reactivated when encountering the same antigen without the help of T helper (Th) cells $(26,27)$.

When the immature $\mathrm{B}$ cell arrives in the spleen, it develops into a marginal zone B cell (MZB) or follicular cell (FOB) (28). MZB cells are implicated in the early rapid response to infection by secreting IgM (29). To characterize miR-146a's effect on B-cell maturation, King et al. used miR-146a-deficient mice to examine splenic B-cell subsets and found that MZB cells decreased in the spleen, while T1 and T2 transitional B cells increased. Therefore,
miR-146a regulates MZB cell development by inhibiting Notch2 pathway through direct targeting of Numb in a T cell-independent (TI) manner (30). miR-155 plays a key role in the mammalian immune system. It can negatively regulate $\operatorname{AID}(31,32)$, whose function is mediating somatic hypermutation and Ig isotype switching. miR-155 is required for the $\mathrm{B}$-cell response to $\mathrm{T}$ cell-dependent and TI antigens. It has been observed that the number of GC B cells is reduced in miR-155-deficient mice. Likewise, the number of GC B cells is increased with an enhanced antibody response in mice having an overexpression of miR-155 (33). B cells lacking miR-155 lead to a reduced GC response and failed secretion of class-switched, high-affinity IgG1 antibody (34).

To evaluate the function of miR-125b on B-cell differentiation, an LPS-treated B-cell line was transfected with a miR-125b mimic. B-cell differentiation into the plasma cell was inhibited as reflected by reduced IgM production. Further studies suggest that miR-125b regulates $\mathrm{B}$-cell responses in the GC through targeting IRF-4 and BLIMP-1 transcription factors (35).

Zhang et al. performed B-cell miRNA profiling using multiplexed real-time PCR to observe the miRNA expression in the mature B-cell subsets. Researchers found that miR-223 expression is highly upregulated in both naïve and memory cells when compared with GC cells. By targeting transcription factors, LMO2 and MYBL1, miR-223 might regulate naïve to GC B-cell transition and GC B cell to memory cell transition (36).

In addition to the above miRNAs which regulate the B-cell development in peripheral, miR-142 has also been proven as a critical molecule to modulate the B-cell ontogenesis (37). In a miR-142 gene-deleted mouse model, the size of splenic B-cell compartment is enlarged, probably due to an immunoproliferative disorder that MZB cell population increased as well as B1 B cell decreased. Moreover, the function of B cells from miR-142 deficiency mice is impaired, manifested by hypoimmunoglobulinemia. And the B-cell homeostasis is controlled by miR-142 through targeting B cell-activating factor receptor (37).

In summary, several miRNAs have been implicated to affect the process of peripheral B-cell development and function, including MZB differentiation, GC response, Ig isotype switching, and somatic hypermutation. These processes are regulated by miRNAs through targeting different transcription factors that are important for antigen-dependent B-cell differentiation and function. Moreover, miRNAs expression profiling during B-cell activation would make us find some new molecules with critical role thus dissecting the profound function of miRNAs in peripheral B-cell development.

\section{miRNAs IN B-CELL TOLERANCE AND AUTOIMMUNITY}

Immune tolerance is a state of unresponsiveness or low reaction of the immune system when encountering antigen. Immune tolerance ensures that the lymphocyte does not recognize its own tissues and only attacks "non-self" antigens. Defects in immune tolerance result in the development of autoimmunity and subsequently results in the attack of the body's own tissues by autoreactive lymphocytes. Autoreactive B cells have been proposed 
as causative factors in several human autoimmune diseases. Examples include rheumatoid arthritis (RA) (38) and systemic lupus erythematosus $(39,40)$. In these two diseases, autoreactive B cells secrete proinflammatory cytokines and autoantibodies that damage the bodies own tissues (41). Although a number of in-depth studies have been conducted on the molecular mechanism of B-cell tolerance and autoimmunity, the role of miRNAs on B-cell tolerance is still unclear. Some studies have shown that miRNA expression in lymphocytes of patients with autoimmune diseases is generally different than those of healthy individuals $(42,43)$. The following miRNAs have shown the potential contribution to B-cell autoimmunity disease.

The miR-17-92 cluster was discovered as the first miRNA cluster to control B-cell tolerance. miR-19, one of the six mature miRNAs encoded by the miR-17-92 cluster, plays a critical role in regulating $\mathrm{B}$-cell tolerance at the immature $\mathrm{B}$ cell. It inhibits the expression of PTEN, which functions as a negative mediator for the PI3K-Akt pathway (15). The role of miR-17-92 in mice was investigated by Xiao et al. Researchers found that transgenic mice with ectopic expression of miR-17-92 developed autoimmunity, producing higher serum autoantibody than control mice. These mice also died prematurely from the autoimmune disease at a higher rate than control mice (44).

Gonzalez-Martin et al. (45) performed a functional screen of individual miRNAs using IgMb-macroself mice transduced with a retroviral miRNA-expression library. They found miR-148a acts as a critical mediator to B-cell tolerance and autoimmunity. Three genes, Gadd45a, Bcl2111, and PTEN, which are implicated in autoimmunity, were identified as miR-148a targets. Moreover, overexpression of miR-148a in lupus model mice can promote the development of a lethal autoimmune disease (45). Therefore, miR-148a may act as an important mediator for B-cell tolerance, as dysregulation of the miR-148a would lead to the development of autoimmune disease.

To investigate the role of miR-210 upon the B-cell activation and function, Mok et al. (46) generated miR-210 deficient and overexpressing mice and found miR-210, induced by Oct-2, act as a fine-tuning molecule to regulate the balance between pathogen elimination and autoimmunity. Mice deficient in miR-210 lead to the development of autoantibodies, whereas mice overexpressing miR-210 result in abnormalities in B-cell subsets and function, especially in decreased B2 cell population and impaired classswitched antibody production (46).

To our knowledge, except the above-mentioned miRNAs, very few studies have addressed the function of individual miRNAs for B-cell tolerance and autoimmunity. And these studies suggested that B-cell tolerance is possibly regulated by miRNA through mediating some molecules that are associated with autoimmunity, such as PTEN, Gadd45a, and Bcl2l11 (15, 44, 45). Although some reports have shown the miRNA expression profile in patients with autoimmune disease, the detailed role of miRNAs on B-cell tolerance is needed to be further explored.

\section{miRNAs IN B-CELL LYMPHOMAS}

Abnormal expression of miRNA is common in some tumors, such as B cell neoplasms. B cell neoplasms develop from mature B cells and constitute the majority of lymphomas and leukemias. There is increasing evidence showing that miRNAs can function both as tumor suppressor genes and oncogenes (47). Many miRNAs are involved not only in the B cell development process, but also in B cell lymphoma development.

As discussed earlier, the miR-17-92 cluster is involved in bone marrow B-cell development and central tolerance. It also, however, shows oncogenic potential. Increased expressions of the miR-17-92 cluster cooperate with oncogene, c-myc, to promote tumor growth in a mouse model of B-cell lymphoma (48). Sandhu et al. generated miR-17-92 B cell-specific transgenic mice with an overexpression of miR-17-92. The penetrance of B-cell lymphoma in these mice was around $80 \%$ by age $12-18$ months, suggesting that miR-17-92 is a strong cancer driver (49).

Though miR-155 has been demonstrated to function in both hematopoiesis and the immune response, it also acts as an oncogenic miRNA in many malignancies (50). Zhang et al. (51) used locked nucleic acid-modified anti-miR-155 to inhibit miR-155 expression in cultured BCWM1 and MEC1 cells in vitro and in vivo of a mouse xenograft model of Waldenstrom macroglobulinemia. Results showed an inhibition of cell survival and cell proliferation. Tumor growth in recipient mice also decreased, proving that miR-155 acts as an oncogenic miRNA in B-cell lymphoproliferative disorders (51). A recent study by Zhu et al. showed that expression levels of miR-155 were increased in lymphoma tumor tissues compared with adjacent normal tissues and those patients with lower miR-155 levels survived longer than those with higher levels (52). In addition, miR-155 has also been found to play an important role in cell proliferation, cell cycle, and apoptosis of DLBCL cell lines. It may regulate biological processes of DLBCL by targeting TGFBR2 (52). Some studies have also focused on the oncogenic role of miR-155 in the pathogenesis of B-cell lymphoma, including the targeting of NIAM, histone deacetylase 4 (HDAC4), SHIP1, and PIK3R1 $(\mathrm{p} 85 \alpha)(53-56)$.

miR-21 functions as a proto-oncogene and contributes to cancerogenesis. miRNA profiling experiments indicate that its expression is upregulated in most tumor types analyzed so far, including human breast cancer, colon adenocarcinoma, and glioblastoma (57-60). Medina et al. have developed a mouse model using Cre and Tet-off technologies to overexpress miR-21. They found that ectopic expression of miR-21 can result in a pre-B lymphoma, which, therefore, suggests that miR-21 is an important oncogene (61).

A study presented by de Yebenes et al. (62) found that miR217 acts as an oncogene in GC B cells. The mir-217 expression is upregulated in GC B cells and miR-217 can promote the GC reaction by stabilizing Bcl-6 expression, therefore, the production of class-switched antibodies and frequency of somatic hypermutation are enhanced. And miR-217 act as an oncomiR that its overexpression can promote the mature B cell lymphomagenesis (62).

In contrast to the oncogenic role of the mir-17-92 clusters, miR-155 miRNA, miR-21 miRNA, and miR-217 in B cell lymphomas, the following miRNAs that will be listed and discussed act as tumor suppressor genes. A study on miR-181a expression in GC B cell (GCB)- and ABC-like DLBCL cell lines and primary tumors showed lower miR-181a levels in the ABC-like subgroup 
compared with the GCB-like subgroup. This was found to be due to miR-181a directly regulating several components of the NF-kB signaling pathway and inhibiting NF-kB activity (63). When xenografts were performed, ABC-like DLBCL xenografts induced with miR-181a displayed a slower tumor growth rate and longer survival than GCB-like DLBCL xenografts. Overall, miR181a negatively regulates oncogenic signaling which decreases cell proliferation and slows tumor growth rate (63).

miR-34a is a well-studied miRNA that acts as a tumor suppressor by linking with the p53 network in tumors (64). In an analysis of miRNA expression profiles from gastric MALT lymphoma and gastric DLBCL, 27 downregulated miRNAs were identified. Of the identified, myc-repressed miR-34a showed the strongest tumor suppressive activity in DLBCL cell lines. miR-34a's tumor suppressive effects could be attributed to downregulate its target, FoxP1 (65). In another study, lymph node tissue was analyzed from 30 DLBCL patients and 30 reactive lymph node hyperplasia patients. miR-34a levels were significantly decreased in DLBCL lymph node tissue compared with control lymph tissue, demonstrating that miR-34a may be involved in the pathogenesis of DLBCL via its regulation on AXL (66).

miR-146a functions as a negative feedback regulator in the NF- $\kappa B$ pathway, where its deficiency in mice can result in the development of lymphoid and myeloid malignancies (67). Using the $\mathrm{E}(\mathrm{mu})-\mathrm{Myc}$ transgenic mouse model, it was shown that miR-146a deficiency can synergize with c-Myc to form tumors and increase mortality in $\mathrm{E}(\mathrm{mu})-\mathrm{Myc}$ mice. The early growth response-1 gene, which mediates hematopoietic differentiation, was identified to be regulated by miR-146a in B cells, suggesting that miR-146a also acts as a tumor suppressive gene to inhibit B-cell oncogenesis (68).

Cluster 15/16 miRNAs lie within chromosome 13q14 and are deleted or downregulated in B-cell chronic lymphocytic leukemias (CLLs). They also function as tumor suppressors through activating intrinsic apoptosis pathway by targeting BCL2 $(69,70)$. Expression of cluster 15/16 miRNAs is downregulated by c-Myc and histone deacetylase in mantle cell lymphoma cell lines. This is also observed in other Myc-expressing B-cell lymphomas (71).

Schneider et al. have investigated the role of miR-28 in B-cell lymphomagenesis (72). They compared the expression of miR-28 in normal and malignant GC B cells and found miR-28 expression is significantly decreased in Burkitt lymphoma (BL). Re-expression of miR-28 is able to reduce the proliferation and clonogenicity of BL cells; this re-expression also affects MYCinduced transformation in MCF10A cells through inhibition of MAD2L1 and BAG1. These results show that miR-28 is a tumor suppressor in BL and its downregulation leads to B-cell lymphomas (72).

Overall, previous studies demonstrated that the miRNAs in B-cell lymphomas can be divided into two groups: oncogenic miRNAs, such as mir-17-92 clusters, miR-155, miR-21, and miR-217 show the potential to initiate the tumor formation, maintenance and promote tumor development; whereas tumor suppressor miRNAs, such as miR-181a, miR-34a, miR-146a, Cluster 15a/16-1 miRNAs, and miR-28 exhibit the role to inhibit cell proliferation and tumor growth. In the future, it would be possible to control the expression of some key miRNAs and, therefore, develop some new therapeutic concept for the treatment of B-cell lymphomas.

\section{THE VALUE OF miRNAs IN DIAGNOSIS, PROGNOSIS, AND THERAPEUTIC POTENTIALS IN B-CELL LYMPHOMAS}

MicroRNAs have been proven to mediate several cellular physiological activities and are closely associated with the formation, progression, and therapeutic response of several types of cancers, including B-cell lymphomas (73). An effective treatment currently used for DLBCL patients is rituximab, cyclophosphamide, hydroxyldaunorubicin (doxorubicin), oncovin (vincristine), and prednisolone regimen (R-CHOP).

Several miRNAs have been reported to affect the tumor sensitivity to specific drugs. For example, Marques et al. found that overexpression of miR-34a using a lentiviral vector can increase the sensitivity of two DLBCL cell lines to doxorubicin (74), and circulating miR-125b and miR-130a in DLBCL is associated with $\mathrm{R}-\mathrm{CHOP}$ resistance (75).

MicroRNAs also have value as biomarkers for clinical diagnosis and prognosis in both CHOP- and R-CHOP-treated DLBCL cohorts $(76,77)$. Recently, Lawrie et al. examined circulating miRNAs in serum from both DLBCL and healthy controls, and found that the level of miR-21, miR-210, and miR-155 was higher in patients than controls. Therefore, these miRNAs may serve as diagnostic markers for DLBCL patients (78). Furthermore, another study investigated the early diagnostic value of circulating miRNAs in DLBCL. The authors measured levels of several miRNAs (including miR-15a, miR-16-1, miR-21, miR-29c, miR$34 \mathrm{a}$, miR-155, and miR-223) in serum samples from DLBCL patients and healthy controls. In comparison with controls, analysis of these levels in DLBCL serum showed upregulation in miR-15a, miR-16-1, miR-21, miR-29c, and downregulation in miR-34a (79).

Researchers have also investigated the association of miRNA expression with clinicopathologic parameters and overall survival of patients. For instance, miR-21 is found to be overexpressed in peripheral blood mononuclear cells of B-cell non-Hodgkin's lymphoma and serum of DLBCL patients. Higher expression of miR-21 is also positively associated with clinical stage and therapeutic outcomes, resulting in worse overall survival $(80,81)$. Conversely, another study evaluating the prognosis of miR-21 in Chinese DLBCL unexpectedly revealed that higher levels of miR-21 were consistent with better prognosis in DLBCL (82). Due to these differing results, the prognostic potential of miR21 on DLBCL should be deeply explored in the future. Further study was performed to observe if miR-21 is able to regulate the cytotoxic effects of the $\mathrm{CHOP}$ chemotherapeutic regimen to the cell line CRL2631. Results showed that decreased miR-21 by antisense oligonucleotides can make DLBCL more sensitive to CHOP regimen (83). Similar results have shown that the miR-21 inhibitor can increase the sensitivity of DLBCL cells to doxorubicin (84). miR-21 can become a potential therapeutic target for B-cell lymphomas.

The value of miR-155 and miR-146a as potential prognostics in DLBCL patients has also been investigated (85). Zhong et al. analyzed the level of miR-155 and miR-146a in formalin-fixed tissue samples of DLBCL patients and found that their expression was higher in the DLBCL patients than in reactive hyperplasia 




FIGURE 1 | Summary of the role of microRNAs in B-cell development and lymphoma and the value in clinical practice.

lymphoid nodes. Further analysis showed that patients with lower expression of miR-155 and miR-146a exhibited longer progression-free survival in the de novo DLBCL. In addition, patients with high levels of miR-155 benefited more from rituximab therapy (85).

Another study performed by Mraz et al. (86) reveal miR-150 can act as the clinicobiological marker to reflect the outcome of CLL disease. It was found that miR-155 regulates two newly identified targets, Foxp1 and GRB2-associated bind protein 1, and both of which regulate the BCR signaling, therefore, affect CLL growth and survival. The CLL patients with higher levels of miR-150 in the blood showed longer treatment-free survival and overall survival (86). Interestingly, as mentioned before, miR-150 might affect the differentiation of pro-B cells to pre-B cells through regulating some potential targets, such as Myb and Foxp1 (18). However, Foxp1, as an essential regulator of early B-cell development (87), is not affected in miR-150 KO or overexpression of B cells; while Myb, an essential transcription factor, acts as the actual target of miR-150 in lymphocyte development (17). This is inconsistent with the findings of Mraz et al. (86) that Foxp1 expression from CLL cells is reduced in patients with relatively high-level compared with low-level expression of miR-150, whereas, Myb expression stay at the low level that is not proportional to miR-150. So it can be speculated that under different physiological and pathological conditions, the cell transcriptome would be different, thus, one single miR-150 can mediate multiple pathophysiological processes by targeting different molecules.
A similar study was performed by Wu et al. (88) to investigate the correlation of miR-146b-5p and the miR-320d expression on the prognosis of DLBCL patients. Results showed that their expression in lower levels was associated with poor clinical outcome, including reduced progression-free survival and overall survival. This is attributed to their inhibitory role in DLBCL cell proliferation (88).

Other studies focused on the relationship between expression of miRNAs and the prognosis of DLBCL patients. For example, low levels of miR129-5p in DLBCL patients have been associated with shorter overall survival (89), while high levels of miR-199a and miR-497 have been correlated with a better overall survival (90). Despite this, patients with high expression of miR-125b indicated poor prognosis along with shorter overall survival (75).

Overall, these studies demonstrated that miRNAs were increasingly recognized as a valuable tool for B cell lymphomas diagnosis, as prognostic markers to predict cancer clinical outcomes, and miRNAs even show the ability to modulate the efficiency in anticancer treatments. Thus miRNAs will show great potential in clinical practice.

\section{CONCLUDING REMARKS}

MicroRNAs are a class of short, non-coding RNA molecules that negatively regulate gene expression by binding to their target mRNAs. The role of miRNAs in B cell physiology and pathology, and its potential in clinical practice are summarized in Figure 1. 
It is clear miRNAs also act as potent regulators of B cell development by regulating the gene expression of several transcription factors that are essential for B cell commitment, proliferation, and differentiation. $\mathrm{B}$ cell malignancies arise from the aberrant expression of proteins, processes of which have been shown to be regulated by miRNAs. However, the definite mechanism of how miRNAs affect the formation and biology of B-cell malignancies is not clear. To further clarify the function of miRNAs in B-cell malignancies, additional studies need to be conducted. Gain- and loss-of-function studies are ideal approaches that may be able to discover the information needed to jumpstart the use of miRNAs in clinical practice. In the future, more studies also need to focus on animal models for consistent and reliable results to enable us to better understand the pathophysiology of B cell malignancies.

In addition, various reports have suggested that miRNAs have the potential as non-invasive biomarkers for diagnosis, prognosis of B cell lymphomas, and even as targets in cancer treatment. Studies reviewed in this paper show that abnormal expression of miRNAs may help better assess patient responses to CHOP and R-CHOP chemotherapy regimens (and overall clinical outcome), which would supply us with better strategies to treat DLBCL. However, in order to further confirm the results and establish optimal cutoff values, it is essential to perform larger cohort studies. Furthermore, some miRNAs show the ability to regulate the sensitivity of DLBCL cells to R-CHOP. Therefore, combining the existing chemotherapeutic strategies with miRNAs might enhance the cytotoxicity of $\mathrm{R}-\mathrm{CHOP}$ regimen, thus increasing the

\section{REFERENCES}

1. Carthew RW, Sontheimer EJ. Origins and mechanisms of miRNAs and siRNAs. Cell (2009) 136(4):642-55. doi:10.1016/j.cell.2009.01.035

2. Bartel DP. MicroRNAs: target recognition and regulatory functions. Cell (2009) 136(2):215-33. doi:10.1016/j.cell.2009.01.002

3. Bartel DP. MicroRNAs: genomics, biogenesis, mechanism, and function. Cell (2004) 116(2):281-97. doi:10.1016/S0092-8674(04)00045-5

4. Ambros V. The functions of animal microRNAs. Nature (2004) 431(7006): 350-5. doi:10.1038/nature02871

5. Krol J, Loedige I, Filipowicz W. The widespread regulation of microRNA biogenesis, function and decay. Nat Rev Genet (2010) 11(9):597-610. doi:10.1038/ nrg2843

6. Montecino-Rodriguez E, Dorshkind K. B-1 B cell development in the fetus and adult. Immunity (2012) 36(1):13-21. doi:10.1016/j.immuni.2011.11.017

7. Fabbri M, Croce CM. Role of microRNAs in lymphoid biology and disease. Curr Opin Hematol (2011) 18(4):266-72. doi:10.1097/MOH.0b013e3283476012

8. Shaffer AL, Lin KI, Kuo TC, Yu X, Hurt EM, Rosenwald A, et al. Blimp-1 orchestrates plasma cell differentiation by extinguishing the mature B cell gene expression program. Immunity (2002) 17(1):51-62. doi:10.1016/S10747613(02)00335-7

9. Rajewsky K. Clonal selection and learning in the antibody system. Nature (1996) 381(6585):751-8. doi:10.1038/381751a0

10. Goodnow CC, Sprent J, Fazekas de St Groth B, Vinuesa CG. Cellular and genetic mechanisms of self tolerance and autoimmunity. Nature (2005) 435(7042):590-7. doi:10.1038/nature03724

11. Nemazee D. Receptor editing in lymphocyte development and central tolerance. Nat Rev Immunol (2006) 6(10):728-40. doi:10.1038/nri1939

12. Chen CZ, Li L, Lodish HF, Bartel DP. MicroRNAs modulate hematopoietic lineage differentiation. Science (2004) 303(5654):83-6. doi:10.1126/science.1091903

13. Tanzer A, Stadler PF. Molecular evolution of a microRNA cluster. J Mol Biol (2004) 339(2):327-35. doi:10.1016/j.jmb.2004.03.065

14. Ventura A, Young AG, Winslow MM, Lintault L, Meissner A, Erkeland SJ, et al. Targeted deletion reveals essential and overlapping functions of the miR-17 through 92 family of miRNA clusters. Cell (2008) 132(5):875-86. doi:10.1016/j.cell.2008.02.019 overall survival of DLBCL patients. So far, there are still few types of research on the detailed mechanisms of correlation in miRNA and R-CHOP effects. Further investigation is needed to clarify the roles of miRNAs in the modulation of R-CHOP treatment and investigate the prognostic potential of individual miRNAs in DLBCL patients. Finally, current reports are mainly conducted in DLBCL cells in vitro. More studies should focus on safety and efficiency of miRNA treatment in xenograft mouse models and in humans to ultimately make sure miRNAs are safe and useful for clinical practice.

\section{AUTHOR CONTRIBUTIONS}

CL organized the article. BZ wrote the draft. WY, ZS, BR, and HM revised the draft. ZX, RL drew the figure and table. QG edited the language, figure and table.

\section{ACKNOWLEDGMENTS}

We gratefully thank Vivian Nguyen and Ghanbar Mahmoodi for editing the manuscript.

\section{FUNDING}

This work was supported by National Natural Science Foundation of China (81722002, 31500709) and Natural Science Foundation of Hubei Province (2015CFA080).

15. Lai MY, Gonzalez-Martin A, Cooper AB, Oda H, Jin HY, Shepherd J, et al. Regulation of B-cell development and tolerance by different members of the miR-17 92 family microRNAs. Nat Commun (2016) 7:12207. doi:10.1038/ ncomms 12207

16. Rao DS, O'Connell RM, Chaudhuri AA, Garcia-Flores Y, Geiger TL, Baltimore D. MicroRNA-34a perturbs B lymphocyte development by repressing the forkhead box transcription factor Foxpl. Immunity (2010) 33(1): 48-59. doi:10.1016/j.immuni.2010.06.013

17. Xiao C, Calado DP, Galler G, Thai TH, Patterson HC, Wang J, et al. miR-150 controls B cell differentiation by targeting the transcription factor c-Myb. Cell (2007) 131(1):146-59. doi:10.1016/j.cell.2007.07.021

18. Zhou B, Wang S, Mayr C, Bartel DP, Lodish HF. miR-150, a microRNA expressed in mature B and T cells, blocks early B cell development when expressed prematurely. Proc Natl Acad Sci U S A (2007) 104(17):7080-5. doi:10.1073/ pnas.0702409104

19. Scott EW, Simon MC, Anastasi J, Singh H. Requirement of transcription factor PU.1 in the development of multiple hematopoietic lineages. Science (1994) 265(5178):1573-7. doi:10.1126/science.8079170

20. Kurkewich JL, Bikorimana E, Nguyen T, Klopfenstein N, Zhang H, Hallas WM, et al. The mirn23a microRNA cluster antagonizes B cell development. J Leukoc Biol (2016) 100(4):665-77. doi:10.1189/jlb.1HI0915-398RR

21. Kong KY, Owens KS, Rogers JH, Mullenix J, Velu CS, Grimes HL, et al. miR-23A microRNA cluster inhibits B-cell development. Exp Hematol (2010) 38(8):629.e-40.e. doi:10.1016/j.exphem.2010.04.004

22. Mehta A, Mann M, Zhao JL, Marinov GK, Majumdar D, Garcia-Flores Y, et al. The microRNA-212/132 cluster regulates B cell development by targeting Sox4. J Exp Med (2015) 212(10):1679-92. doi:10.1084/jem.20150489

23. Shapiro-Shelef M, Calame K. Regulation of plasma-cell development. Nat Rev Immunol (2005) 5(3):230-42. doi:10.1038/nril572

24. Klein U, Tu Y, Stolovitzky GA, Keller JL, Haddad J Jr, Miljkovic V, et al. Transcriptional analysis of the B cell germinal center reaction. Proc Natl Acad Sci U S A (2003) 100(5):2639-44. doi:10.1073/pnas.0437996100

25. Odegard VH, Schatz DG. Targeting of somatic hypermutation. Nat Rev Immunol (2006) 6(8):573-83. doi:10.1038/nri1896

26. Nagasawa T. Microenvironmental niches in the bone marrow required for B-cell development. Nat Rev Immunol (2006) 6(2):107-16. doi:10.1038/nri1780 
27. McHeyzer-Williams LJ, McHeyzer-Williams MG. Antigen-specific memory B cell development. Annu Rev Immunol (2005) 23:487-513. doi:10.1146/ annurev.immunol.23.021704.115732

28. Cariappa A, Tang M, Parng C, Nebelitskiy E, Carroll M, Georgopoulos K, et al. The follicular versus marginal zone B lymphocyte cell fate decision is regulated by Aiolos, Btk, and CD21. Immunity (2001) 14(5):603-15. doi:10.1016/ S1074-7613(01)00135-2

29. Baker N, Ehrenstein MR. Cutting edge: selection of B lymphocyte subsets is regulated by natural IgM. J Immunol (2002) 169(12):6686-90. doi:10.4049/ jimmunol.169.12.6686

30. King JK, Ung NM, Paing MH, Contreras JR, Alberti MO, Fernando TR, et al. Regulation of marginal zone B-cell differentiation by microRNA-146a. Front Immunol (2017) 7:670. doi:10.3389/fimmu.2016.00670

31. Dorsett Y, McBride KM, Jankovic M, Gazumyan A, Thai TH, Robbiani DF, et al. MicroRNA-155 suppresses activation-induced cytidine deaminase-mediated Myc-Igh translocation. Immunity (2008) 28(5):630-8. doi:10.1016/j. immuni.2008.04.002

32. Teng G, Hakimpour P, Landgraf P, Rice A, Tuschl T, Casellas R, et al. MicroRNA-155 is a negative regulator of activation-induced cytidine deaminase. Immunity (2008) 28(5):621-9. doi:10.1016/j.immuni.2008.03.015

33. Thai TH, Calado DP, Casola S, Ansel KM, Xiao C, Xue Y, et al. Regulation of the germinal center response by microRNA-155. Science (2007) 316(5824): 604-8. doi:10.1126/science.1141229

34. Vigorito E, Perks KL, Abreu-Goodger C, Bunting S, Xiang Z, Kohlhaas S, et al. MicroRNA-155 regulates the generation of immunoglobulin class-switched plasma cells. Immunity (2007) 27(6):847-59. doi:10.1016/j.immuni.2007.10.009

35. Gururajan M, Haga CL, Das S, Leu CM, Hodson D, Josson S, et al. MicroRNA $125 \mathrm{~b}$ inhibition of B cell differentiation in germinal centers. Int Immunol (2010) 22(7):583-92. doi:10.1093/intimm/dxq042

36. Zhang J, Jima DD, Jacobs C, Fischer R, Gottwein E, Huang G, et al. Patterns of microRNA expression characterize stages of human B-cell differentiation. Blood (2009) 113(19):4586-94. doi:10.1182/blood-2008-09-178186

37. Kramer NJ, Wang WL, Reyes EY, Kumar B, Chen CC, Ramakrishna C, et al. Altered lymphopoiesis and immunodeficiency in miR-142 null mice. Blood (2015) 125(24):3720-30. doi:10.1182/blood-2014-10-603951

38. Edwards JCW, Szczepanski L, Szechinski J, Filipowicz-Sosnowska A, Emery P, Close DR, et al. Efficacy of B-cell-targeted therapy with rituximab in patients with rheumatoid arthritis. N Engl J Med (2004) 350(25):2572-81. doi:10.1056/ NEJMoa032534

39. Leandro MJ, Edwards JC, Cambridge G, Ehrenstein MR, Isenberg DA. An open study of B lymphocyte depletion in systemic lupus erythematosus. Arthritis Rheum (2002) 46(10):2673-7. doi:10.1002/art.10541

40. Sfikakis PP, Boletis JN, Tsokos GC. Rituximab anti-B-cell therapy in systemic lupus erythematosus: pointing to the future. Curr Opin Rheumatol (2005) 17(5):550-7. doi:10.1097/01.bor.0000172798.26249.fc

41. Shlomchik MJ. Sites and stages of autoreactive $B$ cell activation and regulation. Immunity (2008) 28(1):18-28. doi:10.1016/j.immuni.2007.12.004

42. Shen N, Liang D, Tang Y, de Vries N, Tak P-P. MicroRNAs-novel regulators of systemic lupus erythematosus pathogenesis. Nat Rev Rheumatol (2012) 8(12):701-9. doi:10.1038/nrrheum.2012.142

43. Chauhan SK, Singh VV, Rai R, Rai M, Rai G. Differential microRNA profile and post-transcriptional regulation exist in systemic lupus erythematosus patients with distinct autoantibody specificities. J Clin Immunol (2014) 34(4): 491-503. doi:10.1007/s10875-014-0008-5

44. Xiao C, Srinivasan L, Calado DP, Patterson HC, Zhang B, Wang J, et al. Lymphoproliferative disease and autoimmunity in mice with increased miR-17-92 expression in lymphocytes. Nat Immunol (2008) 9(4):405-14. doi:10.1038/ni1575

45. Gonzalez-Martin A, Adams BD, Lai MY, Shepherd J, Salvador-Bernaldez M, Salvador JM, et al. The microRNA miR-148a functions as a critical regulator of B cell tolerance and autoimmunity. Nat Immunol (2016) 17(4):433-40. doi:10.1038/ni.3385

46. Mok Y, Schwierzeck V, Thomas DC, Vigorito E, Rayner TF, Jarvis LB, et al. miR-210 is induced by Oct-2, regulates B cells, and inhibits autoantibody production. J Immunol (2013) 191(6):3037-48. doi:10.4049/jimmunol.1301289

47. Calin GA, Ferracin M, Cimmino A, Di Leva G, Shimizu M, Wojcik SE, et al. A microRNA signature associated with prognosis and progression in chronic lymphocytic leukemia. N Engl J Med (2005) 353(17):1793-801. doi:10.1056/ NEJMoa050995
48. He L, Thomson JM, Hemann MT, Hernando-Monge E, Mu D, Goodson S, et al. A microRNA polycistron as a potential human oncogene. Nature (2005) 435(7043):828-33. doi:10.1038/nature03552

49. Sandhu SK, Fassan M, Volinia S, Lovat F, Balatti V, Pekarsky Y, et al. B-cell malignancies in microRNA E $\mu$-miR-17 92 transgenic mice. Proc Natl Acad Sci U S A (2013) 110(45):18208-13. doi:10.1073/pnas.1315365110

50. Li J, Wan Y, Ji Q, Fang Y, Wu Y. The role of microRNAs in B-cell development and function. Cell Mol Immunol (2013) 10(2):107-12. doi:10.1038/cmi.2012.62

51. Zhang Y, Roccaro AM, Rombaoa C, Flores L, Obad S, Fernandes SM, et al. LNA-mediated anti-miR-155 silencing in low-grade B-cell lymphomas. Blood (2012) 120(8):1678-86. doi:10.1182/blood-2012-02-410647

52. Zhu FQ, Zeng L, Tang N, Tang YP, Zhou BP, Li FF, et al. MicroRNA-155 downregulation promotes cell cycle arrest and apoptosis in diffuse large B-cell lymphoma. Oncol Res (2016) 24(6):415-27. doi:10.3727/0965040 16X14685034103473

53. Slezak-Prochazka I, Kluiver J, de Jong D, Smigielska-Czepiel K, Kortman G, Winkle M, et al. Inhibition of the miR-155 target NIAM phenocopies the growth promoting effect of miR-155 in B-cell lymphoma. Oncotarget (2016) 7(3):2391-400. doi:10.18632/oncotarget.6165

54. Sandhu SK, Volinia S, Costinean S, Galasso M, Neinast R, Santhanam R, et al miR-155 targets histone deacetylase 4 (HDAC4) and impairs transcriptional activity of B-cell lymphoma 6 (BCL6) in the E mu-miR-155 transgenic mouse model. Proc Natl Acad Sci U S A (2012) 109(49):20047-52. doi:10.1073/pnas. 1213764109

55. Pedersen IM, Otero D, Kao E, Miletic AV, Hother C, Ralfkiaer E, et al. Onco-miR-155 targets SHIP1 to promote TNF alpha-dependent growth of B cell lymphomas. EMBO Mol Med (2009) 1(5):288-95. doi:10.1002/emmm. 200900028

56. Huang X, Shen YL, Liu M, Bi CF, Jiang CS, Iqbal J, et al. Quantitative proteomics reveals that miR-155 regulates the PI3K-AKT pathway in diffuse large B-cell lymphoma. Am J Pathol (2012) 181(1):26-33. doi:10.1016/j.ajpath. 2012.03.013

57. Schetter AJ, Leung SY, Sohn JJ, Zanetti KA, Bowman ED, Yanaihara N, et al. MicroRNA expression profiles associated with prognosis and therapeutic outcome in colon adenocarcinoma. JAMA (2008) 299(4):425-36. doi:10.1001/ jama.299.4.425

58. Iorio MV, Ferracin M, Liu CG, Veronese A, Spizzo R, Sabbioni S, et al. MicroRNA gene expression deregulation in human breast cancer. Cancer Res (2005) 65(16):7065-70. doi:10.1158/0008-5472.CAN-05-1783

59. Si ML, Zhu S, Wu H, Lu Z, Wu F, Mo YY. miR-21-mediated tumor growth. Oncogene (2007) 26(19):2799-803. doi:10.1038/sj.onc.1210083

60. Chan JA, Krichevsky AM, Kosik KS. MicroRNA-21 is an antiapoptotic factor in human glioblastoma cells. Cancer Res (2005) 65(14):6029-33. doi:10.1158/0008-5472.CAN-05-0137

61. Medina PP, Nolde M, Slack FJ. OncomiR addiction in an in vivo model of microRNA-21-induced pre-B-cell lymphoma. Nature (2010) 467(7311):86U119. doi:10.1038/nature09284

62. de Yebenes VG, Bartolome-Izquierdo N, Nogales-Cadenas R, Perez-Duran P, Mur SM, Martinez N, et al. miR-217 is an oncogene that enhances the germinal center reaction. Blood (2014) 124(2):229-39. doi:10.1182/blood-201312-543611

63. Kozloski GA, Jiang XY, Bhatt S, Ruiz J, Vega F, Shaknovich R, et al. miR-181a negatively regulates NF-kappa B signaling and affects activated B-cell-like diffuse large B-cell lymphoma pathogenesis. Blood (2016) 127(23):2856-66. doi:10.1182/blood-2015-11-680462

64. He L, He X, Lim LP, de Stanchina E, Xuan Z, Liang Y, et al. A microRNA component of the p53 tumour suppressor network. Nature (2007) 447(7148): 1130-4. doi:10.1038/nature05939

65. Craig VJ, Cogliatti SB, Imig J, Renner C, Neuenschwander S, Rehrauer H, et al. Myc-mediated repression of microRNA-34a promotes high-grade transformation of B-cell lymphoma by dysregulation of FoxP1. Blood (2011) 117(23):6227-36. doi:10.1182/blood-2010-10-312231

66. Zhong XM, Zhu F, Xu XJ, He JD, Yu XJ, Chen XF, et al. The expression and clinical significance of microRNA-34a in diffuse lager B-cell lymphoma. Int J Clin Exp Med (2016) 9(6):10170-80.

67. Zhao JL, Rao DS, Boldin MP, Taganov KD, O'Connell RM, Baltimore D. NF-kappaB dysregulation in microRNA-146a-deficient mice drives the development of myeloid malignancies. Proc Natl Acad Sci U S A (2011) 108(22):9184-9. doi:10.1073/pnas.1105398108 
68. Contreras JR, Palanichamy JK, Tran TM, Fernando TR, Rodriguez-Malave NI, Goswami N, et al. MicroRNA-146a modulates B-cell oncogenesis by regulating Egr1. Oncotarget (2015) 6(13):11023-37. doi:10.18632/oncotarget.3433

69. Calin GA, Dumitru CD, Shimizu M, Bichi R, Zupo S, Noch E, et al. Frequent deletions and down-regulation of micro-RNA genes miR15 and miR16 at 13q14 in chronic lymphocytic leukemia. Proc Natl Acad Sci U S A (2002) 99(24):15524-9. doi:10.1073/pnas.242606799

70. Cimmino A, Calin GA, Fabbri M, Iorio MV, Ferracin M, Shimizu M, et al. miR-15 and miR-16 induce apoptosis by targeting BCL2. Proc Natl Acad Sci U S A (2005) 102(39):13944-9. doi:10.1073/pnas.0506654102

71. Zhang X, Chen X, Lin J, Lwin T, Wright G, Moscinski LC, et al. Myc represses miR-15a/miR-16-1 expression through recruitment of HDAC3 in mantle cell and other non-Hodgkin B-cell lymphomas. Oncogene (2012) 31(24):3002-8. doi:10.1038/onc.2011.470

72. Schneider C, Setty M, Holmes AB, Maute RL, Leslie CS, Mussolin L, et al. MicroRNA 28 controls cell proliferation and is down-regulated in B-cell lymphomas. Proc Natl Acad Sci U S A (2014) 111(22):8185-90. doi:10.1073/ pnas.1322466111

73. Marques SC, Laursen MB, Bodker JS, Kjeldsen MK, Falgreen S, Schmitz A, et al. MicroRNAs in B-cells: from normal differentiation to treatment of malignancies. Oncotarget (2015) 6(1):7-25. doi:10.18632/oncotarget.3057

74. Marques SC, Ranjbar B, Laursen MB, Falgreen S, Bilgrau AE, Bodker JS, et al. High miR-34a expression improves response to doxorubicin in diffuse large B-cell lymphoma. Exp Hematol (2016) 44(4):238-46. doi:10.1016/j.exphem. 2015.12.007

75. Yuan WX, Gui YX, Na WN, Chao J, Yang XG. Circulating microRNA-125b and microRNA-130a expression profiles predict chemoresistance to R-CHOP in diffuse large B-cell lymphoma patients. Oncol Lett (2016) 11(1):423-32. doi:10.3892/ol.2015.3866

76. Jorgensen LK, Poulsen MO, Laursen MB, Marques SC, Johnsen HE, Bogsted M, et al. MicroRNAs as novel biomarkers in diffuse large B-cell lymphoma a systematic review. Dan Med J (2015) 62(5):A5048.

77. Lim EL, Trinh DL, Scott DW, Chu A, Krzywinski M, Zhao YJ, et al. Comprehensive miRNA sequence analysis reveals survival differences in diffuse large B-cell lymphoma patients. Genome Biol (2015) 16:18. doi:10.1186/s13059014-0568-y

78. Lawrie CH, Gal S, Dunlop HM, Pushkaran B, Liggins AP, Pulford K, et al. Detection of elevated levels of tumour-associated microRNAs in serum of patients with diffuse large B-cell lymphoma. Br J Haematol (2008) 141(5): 672-5. doi:10.1111/j.1365-2141.2008.07077.x

79. Fang C, Zhu D-X, Dong H-J, Zhou Z-J, Wang Y-H, Liu L, et al. Serum microRNAs are promising novel biomarkers for diffuse large B cell lymphoma. Ann Hematol (2012) 91(4):553-9. doi:10.1007/s00277-011-1350-9

80. Li J, Fu R, Yang LP, Tu WP. miR-21 expression predicts prognosis in diffuse large B-cell lymphoma. Int J Clin Exp Pathol (2015) 8(11):15019-24.

81. Sun CM, Luan CF. Overexpression of microRNA-21 in peripheral blood mononuclear cells of patients with B-cell non-Hodgkin's lymphoma is associated with disease stage and treatment outcome. Eur Rev Med Pharmacol Sci (2015) 19(18):3397-402.

82. Chen WQ, Wang H, Chen HM, Liu SY, Lu HD, Kong DY, et al. Clinical significance and detection of microRNA-21 in serum of patients with diffuse large B-cell lymphoma in Chinese population. Eur J Haematol (2014) 92(5):407-12. doi:10.1111/ejh.12263

83. Bai HT, Wei J, Deng C, Yang XY, Wang C, Xu R. MicroRNA-21 regulates the sensitivity of diffuse large B-cell lymphoma cells to the CHOP chemotherapy regimen. Int J Hematol (2013) 97(2):223-31. doi:10.1007/s12185-012-1256-X

84. Go H, Jang JY, Kim PJ, Kim YG, Nam SJ, Paik JH, et al. MicroRNA-21 plays an oncogenic role by targeting FOXO1 and activating the PI3K/AKT pathway in diffuse large B-cell lymphoma. Oncotarget (2015) 6(17):15035-49. doi:10.18632/oncotarget.3729

85. Zhong $\mathrm{H}, \mathrm{Xu} \mathrm{L}$, Zhong JH, Xiao F, Liu Q, Huang HH, et al. Clinical and prognostic significance of miR-155 and miR-146a expression levels in formalin-fixed/paraffin-embedded tissue of patients with diffuse large B-cell lymphoma. Exp Ther Med (2012) 3(5):763-70. doi:10.3892/etm.2012.502

86. Mraz M, Chen L, Rassenti LZ, Ghia EM, Li H, Jepsen K, et al. miR-150 influences B-cell receptor signaling in chronic lymphocytic leukemia by regulating expression of GAB1 and FOXP1. Blood (2014) 124(1):84-95. doi:10.1182/ blood-2013-09-527234

87. Hu H, Wang B, Borde M, Nardone J, Maika S, Allred L, et al. Foxpl is an essential transcriptional regulator of B cell development. Nat Immunol (2006) 7(8):819-26. doi:10.1038/ni1358

88. Wu PY, Zhang XD, Zhu J, Guo XY, Wang JF. Low expression of microRNA-146b-5p and microRNA-320d predicts poor outcome of large B-cell lymphoma treated with cyclophosphamide, doxorubicin, vincristine, and prednisone. Hum Pathol (2014) 45(8):1664-73. doi:10.1016/j.humpath.2014.04.002

89. Hedstrom G, Thunberg U, Berglund M, Simonsson M, Amini RM, Enblad G. Low expression of microRNA-129-5p predicts poor clinical outcome in diffuse large B cell lymphoma (DLBCL). Int J Hematol (2013) 97(4):465-71. doi:10.1007/ s12185-013-1303-2

90. Troppan K, Wenzl K, Pichler M, Pursche B, Schwarzenbacher D, Feichtinger J, et al. miR-199a and miR-497 are associated with better overall survival due to increased chemosensitivity in diffuse large B-cell lymphoma patients. Int J Mol Sci (2015) 16(8):18077-95. doi:10.3390/ijms160818077

Conflict of Interest Statement: The authors declare that the research was conducted in the absence of any commercial or financial relationships that could be construed as a potential conflict of interest.

Copyright (C) 2018 Zheng, Xi, Liu, Yin, Sui, Ren, Miller, Gong and Liu. This is an open-access article distributed under the terms of the Creative Commons Attribution License (CC BY). The use, distribution or reproduction in other forums is permitted, provided the original author(s) and the copyright owner are credited and that the original publication in this journal is cited, in accordance with accepted academic practice. No use, distribution or reproduction is permitted which does not comply with these terms. 